\title{
An analysis of the Modeling and Inventory Support Tool: Yield curves vary with Forest Ecosystem Classification
}

\author{
by Daniel Marina ${ }^{1}$ and Sean C. Thomas ${ }^{2}$
}

\begin{abstract}
Stand-level growth and yield models are essential to assessing sustainable levels of forest harvest; such assessments are supported in Ontario by the Modeling and Inventory Support Tool (MIST), which combines updated yield estimates and predicted successional trajectories to improve yield forecasts in Ontario. Currently, forest management planning and MIST stratifies the landbase by the Standard Forest Unit (SFU), but not ecosite as defined under the Forest Ecosystem Classification (FEC) system. Here we examined variation in MIST's input and output parameters (site index, top height, and basal area) for ecosites that fall within the definition of the PW1 SFU in Central Ontario (white-pine-dominated sites). Ecosites showed significant differences in site index values and top height, but not basal area, results indicating systematic differences in productivity among ecosites within the SFU. These results show that fine-scale variation in edaphic factors, as indicated by ecosite information, correspond to differences in stand productivity, and suggest the importance of a more harmonized approach between yield modeling, SFUs, and the FEC system in Ontario.
\end{abstract}

Key words: empirical yield model, Modeling \& Inventory Support Tool, forest ecosystem classification, Standard Forest Unit, Forestry Research Partnership, sustainable forest management, ecosite

\section{RÉSUMÉ}

Les modèles de croissance et de rendement des peuplements sont essentiels à lévaluation des niveaux durables de récolte forestière, ceux-ci étant déterminés en Ontario à laide de l’outil de modélisation et d’aide à l’inventaire (MIST) qui combine les estimés de rendement mis à jour et les courbes évolutives prédites pour améliorer les estimations des rendements en Ontario. Présentement, la planification de l'aménagement forestier et le MIST stratifient le territoire selon les unités forestières standards (UFS), mais pas selon les écosites tels que définis par la classification des écosystèmes forestiers (CEF). Nous avons étudié la variation des paramètres intrants et sortants du MIST (indice de station, hauteur moyenne supérieure et surface terrière) des écosites qui correspondent à la définition de l'USF PW1 du centre de l'Ontario (sites dominés par le pin blanc). Les écosites ont affiché des différences significatives au niveau des valeurs de lindice de station et de la hauteur moyenne supérieure, mais pas dans le cas de la surface terrière, les résultats démontrant d'importantes différences de productivité entre les écosites de l'UFS. Ces résultats indiquent que la variation identifiée localement dans les facteurs édaphiques, tels qu'indiqués par l'information relative à lécosite, correspond aux différences dans la productivité du peuplement et soulignent l'importance d’avoir une approche plus harmonisée entre la modélisation du rendement, les UFS et le système de CEF de l'Ontario.

Mots clés : modèle empirique de rendement, outil de modélisation et d’aide à l'inventaire, classification des écosystèmes forestiers, unité forestière standard, Partenariat pour la recherche forestière, aménagement forestier durable, écosite

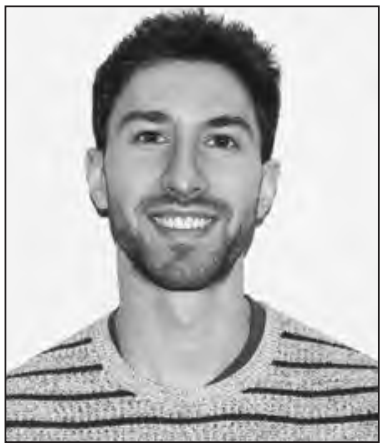

Daniel Marina

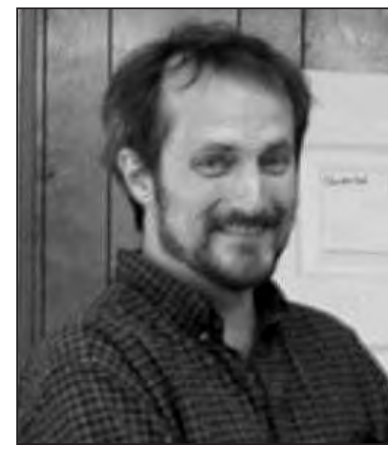

Sean C. Thomas

\section{Introduction}

Growth and yield models employ a system of equations in order to forecast the outcomes of various forest uses, thus aiding long-term management of forest resources (Vanclay 1994, Abitibi Bowater Inc. 2011). Yield prediction models utilize the quantitative relationships that exist among measurable growth parameters in forest stands to predict the future yields of forest types (Armitage 1998). Thus, a principle objective of yield models is to take local information on the potential productivity of a given site into account when scheduling and regulating harvests at levels intended to be sustainable (Armitage 1998).

\footnotetext{
${ }^{1}$ Faculty of Forestry, University of Toronto, 33 Willcocks St., Toronto, Ontario M5S 3B3. E-mail: daniel.marina@utoronto.ca

${ }^{2}$ Professor, Faculty of Forestry, University of Toronto, 33 Willcocks St., Toronto, Ontario M5S 3B3. E-mail: sc.thomas@utoronto.ca
} 
In the province of Ontario there have been many changes in legislation, policy, and planning processes that have rendered the yield tables initially developed by W.L. Plonski in the 1950s insufficient to meet the current needs of forest managers (Payandeh 1991, Penner et al. 2008, Sharma et al. 2008, Penner 2010). As a result, a growing need for the development of more rigorous and updated yield models in the 1990s called for new yield curves that would be updated and locally calibrated for silvicultural treatments in use based on forest composition and site characteristics (Bruemmer 2008, Penner 2010). In the late 1990s, the Forestry Research Partnership (FRP) was created as a partnership between Tembec, the Canadian Forest Service (CFS), and the Ontario Ministry of Natural Resources (OMNR). In 1999 the FRP initiated a project to update yield curves used in forest management planning (Baker et al. 2008, Bell et al. 2008, Bruemmer 2008, Penner 2008). The intent was for these yield curves to incorporate a larger calibration dataset along with more sophisticated statistical methods (Penner 2010). The result was the development of the Modeling \& Inventory Support Tool (MIST) in 2008. MIST is an amalgamation of the Strategic Forest Management Model Tool (SFMMTool) developed by the OMNR, and Modeling Ontario Stand Succession and Yield (MOSSY) developed by the FRP. Permanent Sample Plot (PSP) data from the OMNR went into the calibration of MIST empirical yield curves (Penner 2010). MIST has been implemented as a computer platform designed to aid stand inventory analysis and organization as well as yield analysis, and is intended as the standard for yield prediction on Crown land in Ontario for all species and silvicultural regimes included.

One of the central challenges for forest managers is to achieve sustainability not only of timber resources but also of ecosystem functions, integrity, diversity, and structure (Peng 2000, Treitz and Howarth 2000). A first essential step in this regard is systematic assessment of the ecological system in question (Treitz and Howarth 2000). The Forest Ecosystem Classification (FEC) is a predecessor of the larger Ecological Land Classification (ELC) system in Ontario; these systems are useful for providing a common language to forest managers on the organization of ecological variability in the landscape (Chambers et al. 1997, Treitz and Howarth 2000, Johansen et al. 2007). Much of the classification effort is based on the work from G.A. Hills in the late 1950s (Chambers et al. 1997). Hills recognized that soil and other landscape features have a varied effect on forest growth depending on regional climate (Hills 1960). In light of this, Hills established the Site Regions for Ontario to distinguish areas with similar attributes (Fig. 1). A Site Region is an area in which similar successional changes in vegetation will occur given a similar physiographic site and disturbance event. Site Regions provide foresters a framework upon which to apply management practices and the findings of silvicultural research (Hills 1960). The Central Ontario FEC (COFEC) defines ecosites based on the vegetation community, soil type, and moisture regime within Site Regions 5E and 4E (Chambers et al. 1997; Fig. 1). At present, FEC attributes are not considered in MIST. Rather, MIST organizes stand data according to the standard forest unit (SFU) (Penner 2010). SFUs are essentially aggregations of forest stands defined on the basis of tree canopy com-

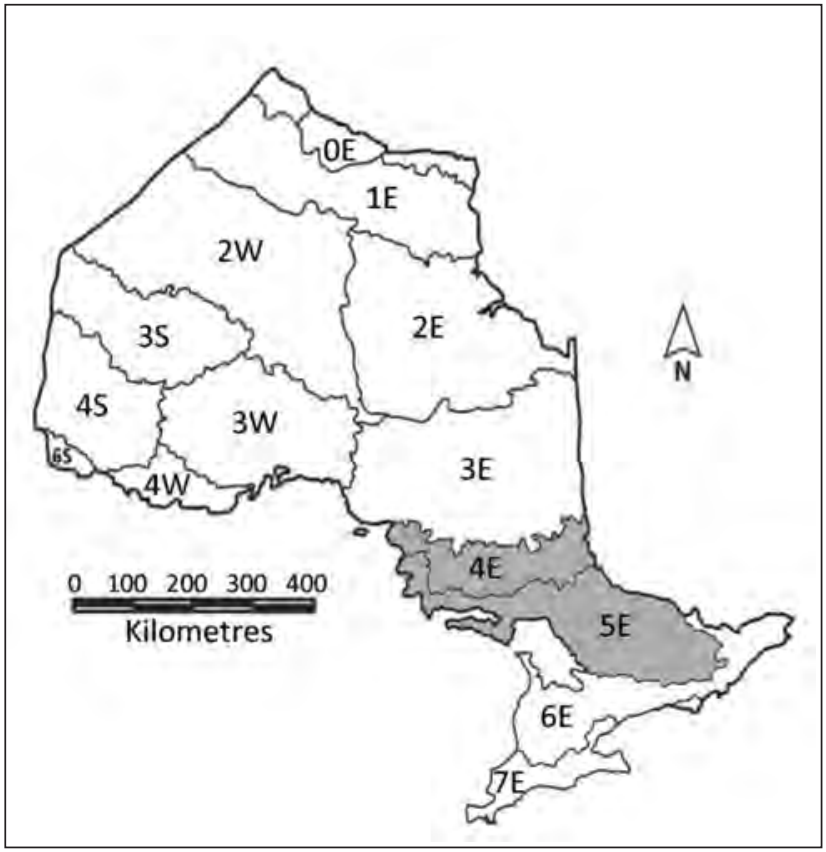

Fig. 1. Site Regions of Ontario as defined by Hills (1960). The COFEC focuses on Site Regions 5E and 4E (shaded) (Environment Canada 2006).

position, eco-region, silvicultural system, and nature of development (Parton et al. 2006, Repath et al. 2009); unlike FEC categories, SFUs do not directly incorporate information on sub-canopy vegetation or edaphic factors.

There is little research in the literature that examines ecosites in relation to stand productivity; however some studies have touched on the related themes. Carmean (1996) tested for relationships between site index and soil types for dominant tree species in the Northwestern Ontario Forest Ecosystem Classification (NWO FEC), but found little evidence for differences among soil types (Carmean 1996). Wang and Huang (2000) observed height and growth patterns of white spruce for the five major natural subregions in Alberta, and found that height was significantly different for one of the subregions, resulting in volume estimation errors up to $25 \%$ when the provincial height and site index curve was applied to this subregion. We are aware of no prior studies that examine ecosite classification with growth and yield model outputs from MIST; however, Pokharel and Dech (2011) have argued more broadly that a phytogeocentric approach to ecological land classification is essential to stratifying landscapes into ecologically meaningful units for management decision-making.

The objective of the present study is to examine variation in productivity among ecosites based on site index, and to determine whether or not ecosites within a given SFU produce unique yield curves in MIST. We make use of observations on site index, top height, and basal area for the ecosites within the PW1 SFU of Ontario's 5E and 4E Site Regions. It is hypothesized that there will be differences in top height and basal area based on ecosite, since ecosites are based on vegetation, soil, and moisture properties, all of which are expected to influence the overall productivity of a stand. 


\section{Methods}

Permanent Sample Plot (PSP) data gathered by the OMNR were analysed. PSPs are $400 \mathrm{~m}^{2}$ plots that measure stand attributes (such as age, basal area, top height, stocking, and species composition) over time (Hopkin et al. 2001). We obtained data on a total of 174 PSPs within the PW1 SFU, the most prevalent SFU represented in Site Region 4E and 5E in Ontario. Typically, PW1 stands are managed under the shelterwood system in Ontario because they have a sufficient basal area of white pine (Pinus strobus L.). This forest unit is usually found on dry to moist, sandy to silty soils of glaciofluvial or morainal origin. The plots span a range of nine different ecosites (see Table 1); a given ecosite was only considered for analysis if it had more than five plots, so some ecosites within the PW1 SFU were excluded. Plots utilized were established in the early 1990s onwards and were selected to cover the full range of conditions for white pine stands. Plots included stands with some historical harvesting impact, but most originated from natural disturbances and are 50 or more years of age. In the COFEC, ecosites with the same domi- nant/co-dominant species composition are given the same whole number (e.g., ecosite 11.1 and ecosite 11.2). The decimal allocated to the ecosite identification indicates variation in the moisture regime and/or soil richness. Ecosites given a decimal value of 2 have greater soil moisture availability compared to ecosites given a decimal value of 1 (Table 1).

\section{MIST simulations}

MIST is a stand-level model (Penner 2010). The user interface has a planning and explorer option for managing data and producing yield curves. The planning option verifies a planning inventory by scanning the records for errors and summarizing them by attributes such as forest type. The explorer option does not conduct this process and is therefore functional for users that do not have an inventory available. MIST outputs behave the same way for both options; however, forest managers will tend to use the planning option if they are producing a forest management plan or annual report (S. McPherson, Forest Productivity Specialist, OMNR, personal communication, 2011). Since the goals of this paper

Table 1: A summary of the dominant canopy species, moisture, and soil for the observed COFEC ecosites (Chambers et al. 1997).

\begin{tabular}{llll}
\hline Ecosite & Dominant canopy species & Moisture & Soil \\
\hline $\mathbf{1 1 . 1}$ & $\begin{array}{l}\text { Pinus strobus L. } \\
\text { Pinus resinosa Ait. }\end{array}$ & Dry to moderately fresh & Sandy to coarse loamy
\end{tabular}

11.2

20.1

20.2

27.1

27.2

\section{Pinus strobus L.}

Pinus resinosa Ait

Pinus banksiana Lamb.

Pinus strobus L.

Pinus resinosa Ait

Pinus strobus L. Populus grandidentata Michx. Quercus rubra L.

Pinus strobus L. Populus grandidentata Michx. Quercus rubra L.

Pinus strobus L. Pinus resinosa Ait Picea glauca (Moench) Voss Intolerant hardwood

Pinus strobus L. Pinus resinosa Ait Picea glauca (Moench) Voss Intolerant hardwood

Acer saccharum Marsh. Betula papyrifera Marsh. Populus spp.

Pinus strobus L.

Acer saccharum Marsh. Betula papyrifera Marsh. Populus spp.

Pinus strobus L.
Fresh to moist

Occasionally very moist

Dry to moderately fresh

Dry to moderately fresh

Fresh to moist

Dry to moderately fresh

Fresh to moist

Occasionally very moist

Dry to moderately fresh

Fresh to moist

Occasionally very moist
Sandy to coarse loamy

Sandy to coarse loamy Very shallow to Shallow

Sandy to coarse loamy Very shallow to shallow On crests and upper and mid slopes

Wide range of soil textures

Sandy to coarse loamy

Sandy to coarse loamy

Sandy to coarse loamy

Wide range of soil textures 
do not require the functions of the planning option, the explorer option was used. It is important to note, however, that the explorer option will only produce an output with age increments of 10 years (from age class 5 to 255). As a result, numerical interpolation was needed for some analyses.

\section{Input parameters}

Site index is a measure of the productivity of a stand, and is commonly summarized as a coarser site class value (Pinto et al. 2007). Site index is the top height of the plot/stand at age 50. Since few plots were measured at this age, extrapolations are necessary to estimate a site index reference number (the expected top height at age 50) (Penner 2010). For this paper, site class (SC) was determined using the following equation:

$$
\text { [1] } S C=(S I-a) / b
$$

where $S I$ is the site index value, and $a$ and $b$ are constants (Penner 2010). White pine is the leading species for PW1 stands, and so the following coefficients were used: $a=24.536$ and $b=-5.354$ (Penner 2010).

Additional input parameters included stocking and species composition. In MIST, stocking is based on the value in the Forest Resources Inventory (FRI), quantified as stand basal area relative to the predicted basal area from normal yield tables for the appropriate species, age, and site class. Stocking is defined as the observed basal area of the stand as a proportion of the normal basal area (for the appropriate species, age, and site class), and is estimated through aerial photographic interpretation by relating crown closure to stocking values calculated in calibration plots (Pinto et al. 2007). In MIST outputs, stocking is held constant and does not change with stand age. Tree species composition is frequently also based on FRI data: generally species are listed to the nearest $10 \%$, and all species contributing at least $10 \%$ occupancy are included (Pinto et al. 2007). Here we used available FEC PSP data for which plots have a minimum species threshold of $1 \%$ occupancy and are calculated from basal area (S. McPherson, personal communication, 2011).

\section{MIST outputs}

Yield indicators such as basal area, top height, density, and volume (gross and net merchantable) are some of the main outputs in MIST. This paper focuses on an analysis of top height and basal area because these outputs can be compared directly with the PSP plot data. All 174 plots were modelled individually in MIST.

Top height in the plot data was estimated to the nearest 1 $\mathrm{m}$ for the dominant tree species or group of similar species. Dominant trees are those that have the greatest estimated basal area in the stand (Pinto et al. 2007). MIST predicts height values from published site index curves that tend to be inaccurate for older age classes (beyond 150 years) (S. McPherson, personal communication, 2011). As a result, MIST outputs for very old stands are expected to be inaccurate; however, only three of the 174 plots used in this study exceeded an age of 150 years. MIST only uses the leading species to produce top height predictions. The top height equation used for white pine (the leading species) in MIST is taken from Parresol and Vissage (1998):
[2]

$$
\begin{aligned}
& \text { topht }=0.3048 \cdot\left[\operatorname { e x p } \left(0.8417 \cdot e^{8.618 \% / \text { Age }}\right.\right. \\
& \left..(\operatorname{In}(S / / 0.3048)-0.5920)-74.7099 / \mathrm{Age}^{+2.0862}\right]
\end{aligned}
$$

where topht $=$ top height in $\mathrm{m}$, and Age is stand age in years. Basal area increases with site index and stocking for even-aged forests. It also increases with age with a quick increase when the stand is young, eventually slowing down and levelling off as the stand develops (Penner 2010). In MIST basal area is calculated as a linear function of stocking and site class and a sigmoidal function of stand age (Penner 2010):

$$
\text { [3] } \hat{B} A=\text { stocking } \cdot\left(a_{0}+a_{1} \cdot \hat{S} I\right) \cdot\left(1-e^{-\beta_{n} B \text { Hage } d^{\pi}}\right)
$$

where $\hat{B} A=$ estimated basal area, stocking is defined as above, $\hat{S} I$ is the estimated site index, BHage is stand age (at breast height), and $a_{0}, a_{1}, b_{0}$, and $g_{0}$ are fitted constants.

\section{Analysis}

Analysis of variance (ANOVA) was used to test for variation in site index by ecosite. Top height and basal area curves predicted by MIST were plotted by ecosite. Since a unique curve was produced for each plot, average values were calculated for each stand age by ecosite category. To examine potential deviations in MIST predictions by ecosite we plotted predicted plot values as a function of observed values by ecosite category. MIST outputs were based on 10-year age categories; therefore, we used a spline function to interpolate the corresponding predicted height and basal area for the exact plot age from MIST outputs. Analysis of Covariance (ANCOVA) was used to analyze deviations in observed vs. predicted basal area and top height by ecosite, with statistical tests examining both differences in intercepts and slopes. Statistical analyses and spline interpolations were performed in the statistical programming language $\mathrm{R}$ v. 2.10 (R Development Core Team 2011).

\section{Results}

There were pronounced site index differences between ecosites (ANOVA F-test: $\mathrm{P}=0.0085$; Fig. 2). The largest observed difference was between ecosite 13.1 (dominated by jack pine [Pinus banksiana Lamb.], white pine, and red pine [Pinus resinosa Ait.] on dry sites with relatively poor soil), which had the lowest mean site index and ecosite 20.2 (dominated by white pine, red pine, and trembling aspen [Populus tremuloides Michx.]), which had the highest. In general, ecosites associated with lower soil moisture (e.g., ecosites $11.1,14.1,20.1)$ had lower site index values than corresponding sites with similar species composition but higher soil moisture (e.g., ecosites 11.2, 14.2, 20.2). The exception to this pattern was the one pair of ecosites with an appreciable hardwood component (ecosites 27.1 and 27.2).

Average MIST basal area predictions (Fig. 3) paralleled results for site index, with ecosite 13.1 showing the lowest projected basal area, and ecosite 20 the highest. Likewise, ecosites with greater moisture and/or soil richness had higher projected basal area values on average. For all ecosites, projected basal area levelled off around stand maturity (age 80 to 


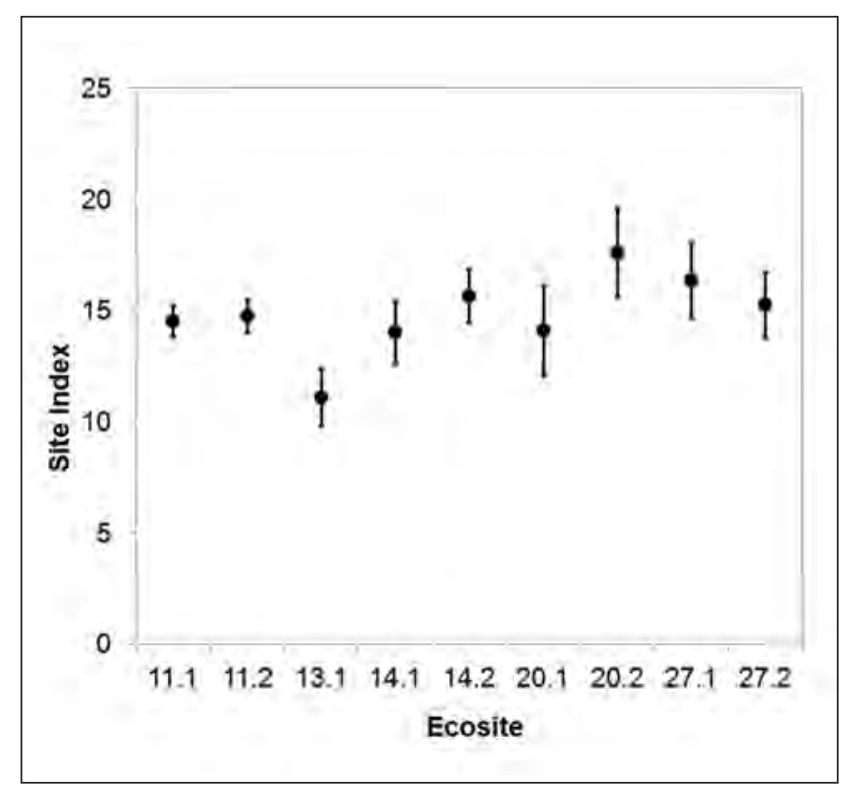

Fig. 2. Variation in site index by ecosite. Means are plotted $\pm 95 \%$ confidence interval.

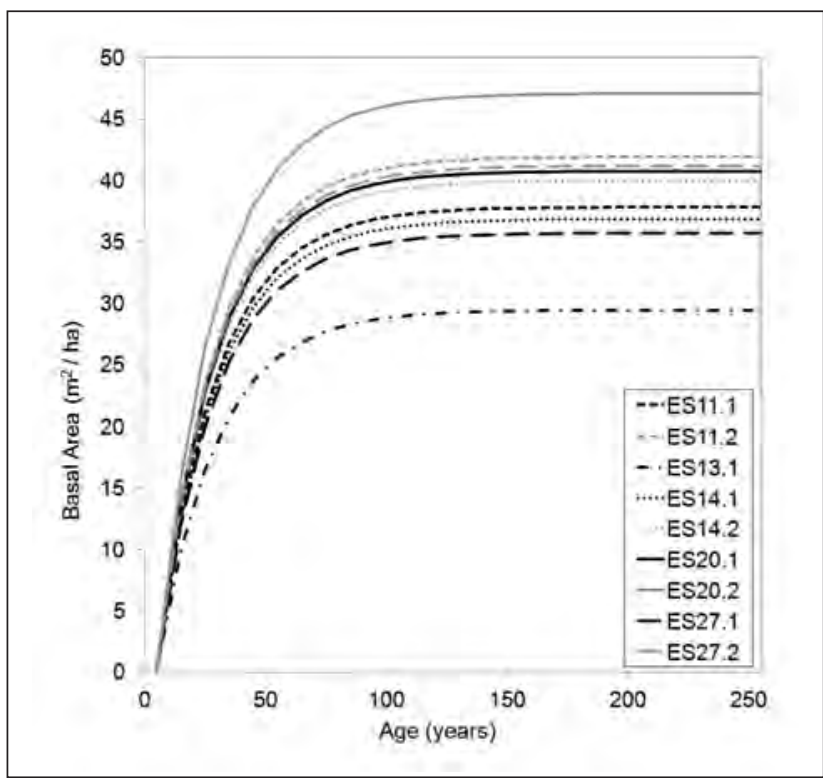

Fig. 3. MIST outputs for mean basal area projections by ecosite. Ecosites classified with the same dominant species composition are shown with the same line pattern but different shading (e.g., 11.1 and 11.2$]$

100 years) but did not decline as stands become over-mature and trees die off, reflecting constraints of model equations incorporated within MIST. Average top height projections showed similar differences among ecosites to those found for basal area (Fig. 4) indicate. The equation MIST uses to predict top height does not produce curves that level off once the stand reaches maturity. The maximum top height observed in the PSP data used for the paper was $37 \mathrm{~m}$ at age 109 for a stand classified as ecosite 20.2. Other plots reached top heights around $34 \mathrm{~m}$ by age 90 . The oldest plot in the dataset was ES20.1 (at age 205) with a top height of $35 \mathrm{~m}$.

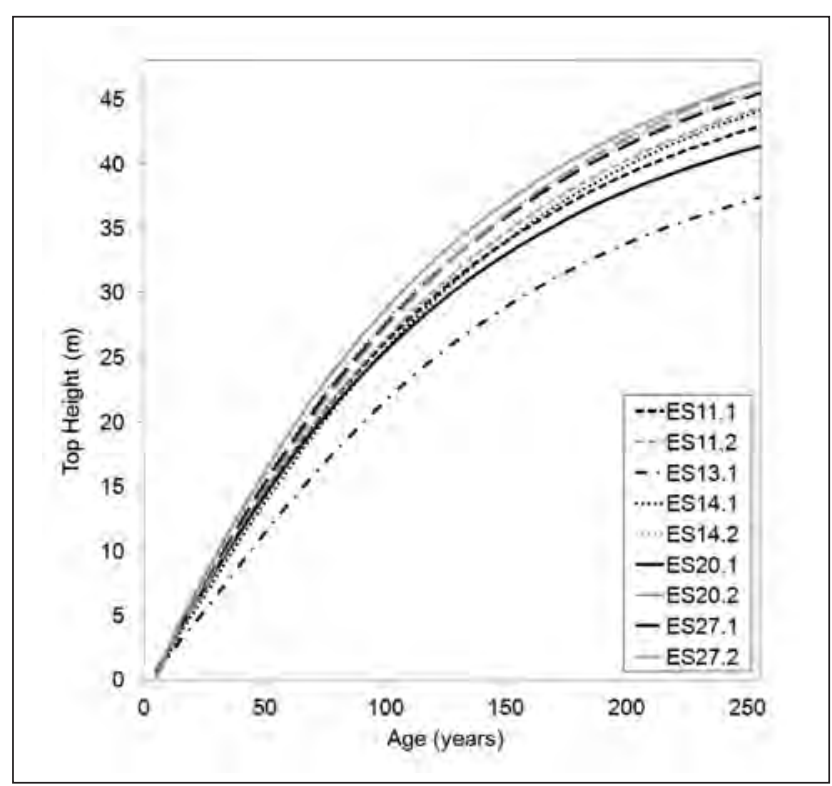

Fig. 4. MIST outputs for mean top height stratified by ecosite. Ecosites are distinguished by variations in line shading and pattern. Ecosites classified with the same dominant species composition are shown with the same line pattern but different shading (e.g., 11.1 and 11.2).

Plots of observed vs. predicted basal area indicate that some plots are both over- and under-predicted by MIST, but but no significant variation in slope or intercept values among ecosites was found (ANCOVA ecosite term: $\mathrm{P}=0.697$; interaction term: $\mathrm{P}=0.494)$. In contrast, results for top height (Fig. 6) do show a significant effect of ecosite (ANCOVA ecosite term: $\mathrm{P}=0.003$; interaction term: $\mathrm{P}=0.009)$. The largest divergences of observed vs. predicted values were observed for ecosite 20.1 and ecosite 20.2.

\section{Discussion}

As predicted, systematic differences in site index were detected among ecosites within a common Standard Forest Unit. These differences corresponded to variation among ecosites in projected growth patterns using MIST. Ecosite classifications indicating moist soil conditions (with otherwise similar tree species composition) generally showed higher projected growth than those indicating dry soil conditions. Relationships between observed data and MIST projections of stand height (but not basal area) also showed systematic deviations related to ecosite,. Overall, the results suggest that it is possible to fine-tune MIST outputs based on ecosite, but also that differences among ecosites are not seen for all outputs.

The ecosites examined in this study cover a wide spectrum of white-pine-dominated stands that varied in co-dominant species, moisture, and soil richness. It is thus not particularly surprising that there would be differences in productivity. We quantified these differences using site index, which is widely employed to assess overall stand productivity or quality (Pokharel and Dech 2011), but which has some recognized limitations. Site index is an indirect measurement due to the fact that the top height at age 50 can only be directly meas- 


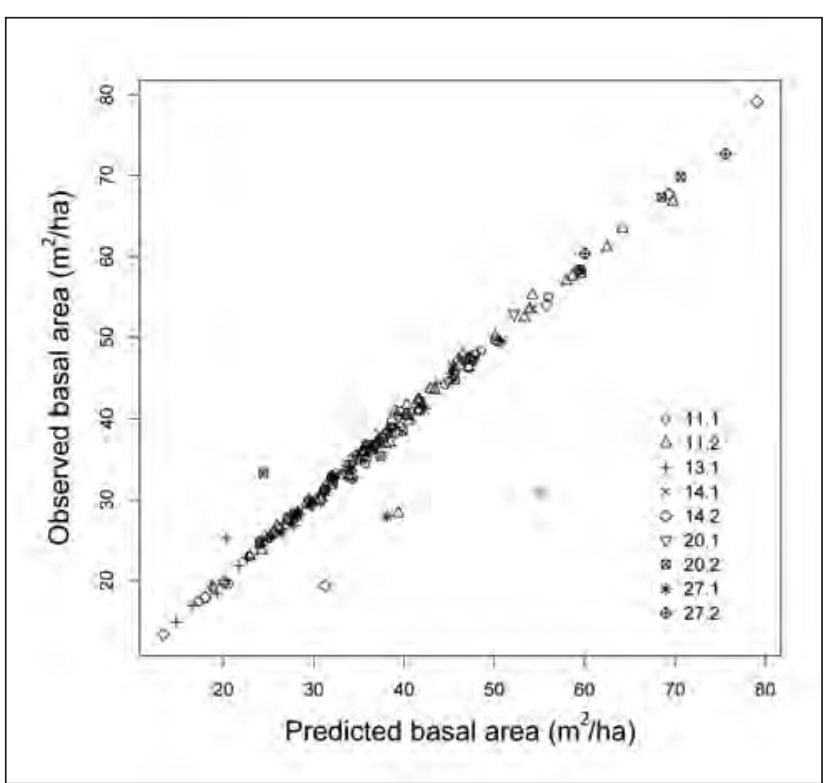

Fig. 5. Plot of observed vs. predicted basal area based on MIST outputs. Ecosites are distinguished by point type with each point representing an individual plot.

ured for stands of that age; it also demands a qualitative classification of trees as dominant and co-dominant (McDill 1999). Assessment of stand age introduces additional uncertainty, particularly in the case of multi-cohort stands. In addition, site index for one species may not work well for another species, as different species are suited to different habitats and environmental characteristics (McDill 1999). Since ecosite classification is itself based in part on species composition (Chambers et al. 1997), it is likely that differences in productivity among species, in addition to ecosite-related variation in site factors, contribute to the observed variation in site index in the present study.

Analyses did not detect significant differences among ecosites for the relationship between observed and predicted basal area, even though the MIST outputs showed greater variation among ecosites for basal area than for top height. One possible explanation for this is that basal area is calculated in MIST by taking the stocking value into consideration, thereby putting less emphasis on site index. In addition, it may simply be that site index, which is calculated on the basis of height growth, does not have as large an effect on a stand's basal area. Further analyses should examine variation among ecosites in volume outputs, which are expected since top height is an important factor in calculating volume yields. In addition, rigorous assessment of MIST more generally must involve direct evaluation of its ability to forecast future growth and yield.

In conclusion, observations in this study indicate that ecosites within SFU categories (at least in the case of PW1) vary in productivity, and thus that ecosite classification includes information that may improve projections of stand growth and yield. Ecosites serve as the basis for describing forest wildlife habitat units and landscape units (Parton et al. 2006). They are thus important indicators of the suitable habitat supply and landscape diversity (Parton et al. 2006). The most likely parameter in MIST that could incorporate some

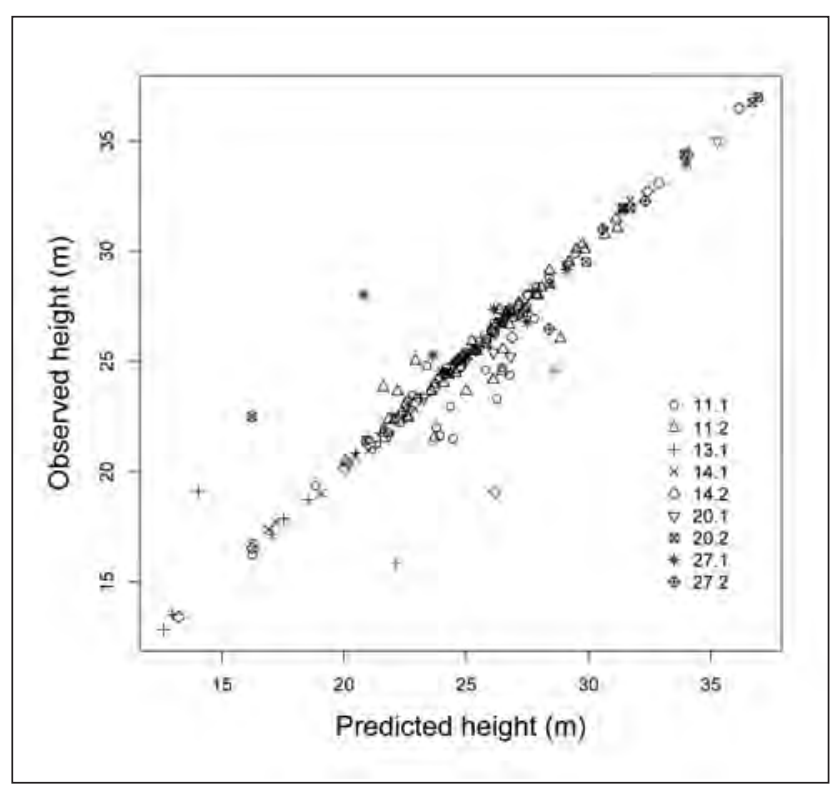

Fig. 6. Plot of observed vs. predicted top height based on MIST outputs. Ecosites are distinguished by point type with each point representing an individual plot.

aspect of FEC would be the SFU definitions (M. Penner, Forest Analysis Ltd., personal communication, 2011). Species composition is an important component of ecosite classification; however, MIST currently only uses the leading species from stand data to produce site index curves, basal area, and top height outputs. Basing SFU definitions more directly on ecosite information would potentially allow for yield curve projections that are more fine-tuned to local conditions. However, there must be a balance in this fine-tuning, as the quantity of SFUs that are used in forest management must be manageable. Furthermore, other components of MIST may be sensitive to the total number of SFUs being modeled. Nevertheless, our results provide further incentive for a harmonization between yield modeling, methods of collecting FRI data and defining standard forest units, and forest ecosystem classification. In addition to improving quantitative projections of growth and yield, this harmonization seems likely to benefit many other aspects of sustainable forest management.

\section{Acknowledgments}

We thank the Canadian Institute of Forestry, the Forestry Research Partnership, and the Canadian Ecology Centre for hosting the internship that resulted in this project, and Scott McPherson, Margaret Penner, Al Stinson and Tat Smith for helpful input on the project.

\section{References}

Abitibi Bowater Inc. 2011. Growth and Yield [online]. Available from http://www.bowater.ca/environment/land.aspx? $\mathrm{id}=147$ [Accessed 09/10/2011].

Armitage, I. 1998. Guidelines for the management of tropical forests 1: The production of wood. Food and Agriculture Organization of the United Nations. Forestry Paper N0. 135. 307 p.

Baker, J.A., W.F. Bell and A. Stinson. 2008. Ontario's Forestry Research Partnership: Progress and next steps. For. Chron. 84: 756-763. 
Bell, W.F., J. Parton, N. Stocker, D. Joyce, D. Reid, M. Wester, A. Stinson, G. Kayahara and B. Towill. 2008. Developing a silvicultural framework and definitions for use in forest management planning and practice. For. Chron. 85: 678-693.

Bruemmer, G. 2008. The Forestry Research Partnership: Developing the partnership. For. Chron. 84: 648-652.

Carmean, W.H. 1996. Forest Site-Quality Estimation Using Forest Ecosystem Classification in Northwestern Ontario. Environ. Mon. Assess. 39: 493-508.

Chambers, B., B.J. Naylor, J. Nieppola, B. Merchant and P. Uhlig. 1997. Field Guide to Forest Ecosystems of Central Ontario. Queen's Printer for Ontario. 200 p.

Environment Canada. 2006. Great Lakes Wetlands Conservation Action Plan Highlights Report 2003-2005. Environment Canada, Toronto, Ontario. 24 p.

Hills, G.A. 1960. Regional Site Research. For. Chron. 36(4): 401-423.

Hopkin, A., A. Fenech, H. Liljalehto, D. McLaughlin and T. Williams. 2001. The Ontario Forest Health Data Co-operative. Environ. Mon. Assess. 67: 131-139.

Johansen, K., N.C. Coops, S.E. Gergel and Y. Stange. 2007. Application of high spatial resolution satellite imagery for riparian and forest ecosystem classification. Remote Sens. Environ. 110: 29-44.

McDill, M.E. 1999. Forest Resource Management Chapter 5: Growth and Yield. Penn State School of Forest Resources. pp. 80-83. Parresol, B.R. and J.S. Vissage. 1998. White pine site index for the southern forest survey. Research Paper SRS-10. U.S. Department of Agriculture, Forest Service, Southern Research Station, Asheville, NC. 8 p.

Parton, J., G. Vasiliauskas, G. Lucking and W.R. Watt. 2006. Standard Forest Units for Northeastern Ontario Boreal Forests. Ont. Min. Nat. Res., Northeast Sci. Info., North Bay, ON. Tech. Note NO. 21. 23 p.

Payandeh, B. 1991. Plonski's (metric) yield tables formulated. For. Chron. 5: 545-546.
Peng, C. 2000. Understanding the role of forest simulation models in sustainable forest management. Environ. Impact Assess. Rev. 20: 481-501.

Penner, M. 2008. Yield prediction for mixed species stands in boreal Ontario. For. Chron. 84: 1-7.

Penner, M. 2010. MIST Yield Curves: Technical Background. The Forestry Research Partnership. 21 p.

Penner, M., M. Woods, J. Parton and A. Stinson. 2008. Validation of empirical yield curves for natural-origin stands in boreal Ontario. For. Chron. 84: 704-717.

Pinto, F., M. Ter-Mikaelian, J-M. Sobze and D. Rouillard. 2007. A method to validate stand attributes in a forest resource inventory: Case study in Nipissing Forest, Ontario. Forest Research Report No. $166.17 \mathrm{p}$.

Pokharel, B. and J.P. Dech. 2011. An ecological land classification approach to modeling the production of forest biomass. For. Chron. 87: 23-32.

R Development Core Team. 2011. R: A language and environment for statistical computing. R Foundation for Statistical Computing, Vienna, Austria.

Repath, D., S. Sullivan and R. Martel. 2009. Forest Management Plan for the Superior-Martel Forest, Part 1. Section 2. p. 114-116.

Sharma, M., J. Parton, M. Woods, P. Newton, M. Penner, J. Wang, A. Stinson and W.F. Bell. 2008. Ontario's forest growth and yield modelling program: Advances resulting from the Forestry Research Partnership. For. Chron. 84: 694-703.

Treitz, P. and P. Howarth. 2000. High Spatial Resolution Remote Sensing Data for Forest Ecosystem Classification: An Examination of Spatial Scale. Remote Sens. Environ. 72: 265-289.

Vanclay, J.K. 1994. Modelling forest growth and yield: applications to mixed tropical forests. CAB International, Wallingford, UK. 312 p.

Wang, G.G. and S. Huang. 2000. Height and growth pattern of white spruce in natural subregions in Alberta, Canada. For. Ecol. Manage. 134: 271-279. 